\title{
Hypertriglyceridaemia and low plasma HDL in a patient with apolipoprotein A-V deficiency due to a novel mutation in the APOA5 gene
}

\author{
- C. Priore Oliva ${ }^{1}$, F. Carubbi ${ }^{2}$, F. G. Schaap ${ }^{3}$, S. Bertolini ${ }^{4}$ \& S. Calandra ${ }^{1}$ \\ From the ${ }^{1}$ Department of Biomedical Sciences, University of Modena \& Reggio Emilia; ${ }^{2}$ Department of Internal Medicine, \\ Endocrinology and Metabolism, University of Modena \& Reggio Emilia, Modena, Italy, ${ }^{3}$ AMC Liver Center, Amsterdam, \\ The Netherlands, and ${ }^{4}$ Department of Internal Medicine, University of Genova, Genova, Italy
}

Abstract. Priore Oliva C, Carubbi F, Schaap FG, Bertolini S, Calandra S (University of Modena \& Reggio Emilia, Modena, Italy; AMC Liver Center, Amsterdam, The Netherlands; University of Genova, Genova, Italy). Hypertriglyceridaemia and low plasma HDL in a patient with apolipoprotein A-V deficiency due to a novel mutation in the APOA5 gene (Case Report). J Intern Med 2008; 263: 450-458.

APOA5 encodes a novel apolipoprotein (apo A-V) which appears to be a modulator of plasma triglyceride (TG). In apoA5 knock out mice plasma TG level increases almost fourfold, whereas in human APOA5 transgenic mice it decreases by $70 \%$. Some SNPs in the APOA5 gene have been associated with variations in plasma TG in humans. In addition, hypertriglyceridaemic (HTG) patients have been identified who carried rare nonsense mutations in the APOA5 gene (Q139X and Q148X), predicted to result in apo A-V deficiency. In this study we report a 17 -year-old male with high TG and low high density lipoprotein choles- terol (HDL-C), who at the age of two had been found to have severe HTG and eruptive xanthomas suggesting a chylomicronaemia syndrome. Plasma postheparin LPL activity, however, was normal and no mutations were found in $L P L$ and $A P O C 2$ genes. The sequence of $A P O A 5$ gene revealed that the patient was homozygous for a point mutation (c.289 C>T) in exon 4, converting glutamine codon at position 97 into a termination codon (Q97X). Apo A-V was not detected in patient's plasma, indicating that he had complete apo A-V deficiency. The administration of a low-fat and low-oligosaccharide diet, either alone or supplemented with $\omega-3$ fatty acids, started early in life, reduced plasma TG to a great extent but had a negligible effect on plasma HDL-C. Loss of function mutations of APOA5 gene may be the cause of severe HTG in patients without mutations in $L P L$ and $A P O C 2$ genes.

Keywords: apolipoprotein A-V deficiency, high density lipoproteins, hypetriglyceridaemia, lipoprotein lypase.

\section{Introduction}

Hypertriglyceridaemia (HTG) usually refers to fasting plasma triglyceride (TG) level above the 95th percentile for age and sex; it can be divided into primary and secondary type. Primary HTG is assumed to have a strong genetic basis; however, the molecular defect underlying primary HTG is known in $<10 \%$ of cases [1].
Hyperlipidaemia type I and hyperlipidaemia type V are lipoprotein disorders characterized by the pathological presence of chylomicrons in the fasting state. Their clinical features include eruptive xanthomas, lipaemia retinalis, hepato-splenomegaly, recurrent abdominal pain and increased risk of pancreatitis [2]. The accumulation of chylomicrons (type I) or chylomicrons and VLDL (Type V) is caused by defects in the lipolytic cascade due to loss of function mutations 
in the genes encoding lipoprotein lipase $(L P L)$ or its activator apo C-II (APOC2) [2].

Familial HTG (hyperlipoproteinaemia type IV) is characterized by an isolated elevation of VLDL. This disorder has a population prevalence of $5-10 \%$ but its molecular basis is still unknown; it is likely to be polygenic and strongly affected by environmental factors and metabolic stress [1].

In familial combined hyperlipidaemia (FCHL) the elevation of plasma TG is due to increased level of VLDL, which is associated with increased level of LDL and hepatic overproduction of apolipoprotein B [3]. The molecular basis underlying FCHL is largely unknown; genetic variants in $A P O A 1 / C 3 / A 4 / A 5$ cluster and in the recently identified USF1 gene appear to contribute to the phenotype $[4,5]$.

The increased TG levels found in dysbetalipoproteinaemia (hyperlipoproteinaemia type III) is due to the accumulation of TG-rich lipoprotein remnants (e.g. $\beta$ VLDL). Patients with this disorder are typically homozygous for the rare apo E-2 isoform, which shows a defective binding to LDL-receptor when compared with the most common apo E-3 isoform. The phenotypic expression of dysbetalipoproteinaemia, however, requires some additional factors such as obesity, type 2 diabetes or hypothyroidism [3].

The recently identified APOA5 gene, which encodes apolipoprotein A-V (apo A-V), appears to be a key modulator of plasma TG homeostasis in rodents as well as in humans. When the human APOA5 gene was expressed in transgenic mice, the plasma TG level decreased by $70 \%$, whereas when mouse apoa 5 gene was inactivated, the plasma TG increased fourfold, compared with control mice [6]. These results suggested an inverse correlation between apo A-V concentration and plasma TG level in mice. Single nucleotide polymorphisms in the APOA5 gene (e.g. $1131 \mathrm{~T} / \mathrm{C}$ in the $5^{\prime}$-flanking region and c.56 C/G in the coding region) have been associated with differences in plasma TG levels in humans [6-10]. Carriers of the rare alleles $-1131 \mathrm{C}$ or c.56 $\mathrm{G}$ have higher plasma TG than carriers of the corresponding common alleles [7-10]. Interestingly, human studies do not support the inverse correlation between plasma apo $\mathrm{A}-\mathrm{V}$ and $\mathrm{TG}$ concentration that has emerged from studies in mice. In fact, plasma apo A-V level was found to be positively correlated with TG level in subjects from the general population, as well as in patients with HTG and in patients with type 2 diabetes [11-16].

Rare loss of function mutations in APOA5 gene have been reported in humans [17]. In 2005 we identified a 9-year-old boy with severe HTG, who was homozygous for a nonsense mutation predicted to result in truncated apo A-V (Q148X) [18]. He was regarded to have complete apo A-V deficiency as no apo A-V was detected in his plasma [17]. Another patient with type V hyperlipidaemia and recurrent episodes of pancreatitis was found to be homozygous for a different apo A-V mutation (Q139X) predicted to cause complete apo A-V deficiency [19]. So it looks as though apo A-V deficiency in humans recapitulates, to some extent, the plasma lipid abnormalities observed in apoa 5 knock-out mice, suggesting that the absence of apo A-V causes a substantial disruption of the metabolism of TG-rich lipoproteins.

In the present study we report a 17-year-old patient with primary HTG detected early in life, who was found to be homozygous for a novel nonsense mutation of APOA5 gene. No apo $\mathrm{A}-\mathrm{V}$ was detectable in his plasma, thus suggesting that he has complete apo A-V deficiency.

\section{Methods}

Subject

Proband T.L. is a 17-year-old Caucasian male, who at the age of two was found to have eruptive cutaneous xanthomas and severe HTG in the fasting state, suggesting hyperchylomicronaemia syndrome. He never had abdominal pain, hepatosplenomegaly nor pancreatitis and developed normally. Routine laboratory tests, with the exception of plasma lipids, were within the reference range. The proband has been treated with low-fat and low-oligosaccharide diet since infancy; 
the good compliance to this diet was associated with a substantial reduction of plasma TG level (Table 1) and a progressive disappearance of eruptive xanthomas. At the age of 12 he started treatment with $\omega-3$ fatty acids $\left(3 \mathrm{~g} \mathrm{day}^{-1}\right)$ which, however, was discontinued after 2 years because of poor compliance. Medium Chain Triglycerides (MCT) supplementation or fibrate therapy were never prescribed.

At age 16 the proband was referred to the Lipid Clinic of the University Hospital with the clinical diagnosis of primary severe HTG (type V). Alcohol assumption was denied. He was a nonsmoker and practised regular physical activity (basketball player). On physical examination he was found healthy and lean (BMI $19.5 \mathrm{~kg} \mathrm{~m}^{-2}$, waist circumference $71 \mathrm{~cm}$ ). He had normal blood pressure and heart rate; no skin, tendons, thoracic, abdominal or vascular abnormalities were observed. Tonsils, eyes and fundus oculi examinations were normal. Abdominal ultrasound scan confirmed the absence of visceral abnormalities. Routine laboratory tests for hepato-biliary, renal and

Table 1 Plasma lipids and lipoproteins in proband T.L.

\begin{tabular}{llclllcc}
$\begin{array}{l}\text { Years } \\
\text { of age }\end{array}$ & Treatment & TG & T-C & HDL-C & LDL-C & Apo B & Apo A-I \\
\hline 2 & None & 9.65 & 5.58 & 0.59 & n.d. & n.d. & n.d. \\
3 & Diet & 2.82 & 4.73 & 0.58 & n.d & n.d & n.d. \\
4 & Diet & 3.59 & 5.68 & 0.80 & 1.47 & 175 & 118 \\
5 & Diet & 5.13 & 4.60 & 0.59 & n.d. & n.d. & n.d. \\
10 & Diet & 3.61 & 3.18 & 0.67 & 1.49 & 123 & 173 \\
11 & Diet & 5.08 & 4.34 & 0.88 & n.d. & n.d. & n.d. \\
12 & Diet $+\omega-3$ & 3.73 & 4.48 & 0.90 & n.d. & n.d. & n.d. \\
13 & Diet $+\omega-3$ & 2.37 & 3.18 & 0.64 & n.d. & n.d. & n.d. \\
13 & Diet & 4.02 & 4.37 & 0.82 & 1.57 & 102 & 126 \\
14 & Diet & 5.28 & 4.19 & 0.69 & n.d. & n.d. & n.d. \\
15 & Diet & 12.03 & 4.96 & 0.59 & n.d. & n.d. & n.d. \\
16 & Diet & 5.90 & 4.08 & 0.75 & 1.73 & n.d. & n.d. \\
17 & Diet $+\omega-3$ & 2.98 & 3.93 & 0.75 & 1.68 & 80 & 112
\end{tabular}

Plasma level of TG, T-C, HDL-C and LDL-C are given in $\mathrm{mmol} \mathrm{L}^{-1}$; plasma level of apo $\mathrm{B}$ and apo A-I are given in $\mathrm{mg} \mathrm{dL}^{-1}$.

Diet $+\omega-3$ fatty acids $3 \mathrm{~g} \mathrm{day}^{-1}$ (oral ethyl-ester of polyunsaturated fatty acids EPA and DHA $85 \%$, EPA/DHA $=0.9-1.5$ ).

n.d., not determined. thyroid function were normal, as well as blood glucose and blood cell count. ECG was normal.

On a low-fat diet, the level of total cholesterol (T-C), TG and HDL cholesterol (HDL-C) were 4.08, 5.90 and $0.75 \mathrm{mmol} \mathrm{L}^{-1}$, respectively (Table 1 ). The addition of $\omega-3$ fatty acids $\left(3 \mathrm{~g} \mathrm{day}^{-1}\right)$ lowered triglycerides to $2.98 \mathrm{mmol} \mathrm{L}^{-1}$ but had little effect on plasma HDL-C (Table 1).

Proband's parents were apparently unrelated; they were in good health and had no family history of dyslipidaemia or premature coronary heart disease. The proband's 7-year-old brother was also in good health. Routine laboratory tests of these family members were within the normal values (Table 2).

\section{Plasma lipid analysis and LPL assay}

T-C, HDL-C, TG, apo A-I and apo B levels were determined by standard methods and plasma lipoprotein were separated by density gradient ultracentrifugation in a SW41 Beckman rotor at $170000 \times g$ at $15^{\circ} \mathrm{C}[20]$. The measurement of plasma apo A-V and apo C-III was performed by ELISA assay; immunoblot analysis of plasma apo A-V was conducted as described [11]. Lipoprotein and hepatic lipase activities in postheparin plasma were measured as previously reported [18].

\section{Analysis of candidate genes}

Genomic DNA was extracted from peripheral blood leucocytes by a standard procedure. All exons and the promoter region of $L P L$ and $A P O C 2$ genes were amplified by polymerase chain reaction from genomic

Table 2 Plasma lipids and lipoproteins in proband's family members

\begin{tabular}{lllllll}
\hline Subject & TG & T-C & HDL-C & LDL-C & Apo B & Apo A-I \\
\hline Father & 0.79 & 5.85 & 1.26 & 4.54 & 128 & 154 \\
Mother & 1.27 & 4.25 & 1.21 & 2.86 & 78 & 157 \\
Brother & 0.56 & 3.69 & 1.03 & 2.74 & 68 & 127
\end{tabular}

Plasma level of TG, T-C, HDL-C and LDL-C are given in $\mathrm{mmol} \mathrm{L}^{-1}$; plasma level of apo $\mathrm{B}$ and apo A-I are given in

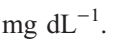


DNA and sequenced as described [18]. The APOA5 gene was amplified and sequenced as reported [18]. The mutation of APOA5 gene found in the proband, which eliminates a PstI restriction site in exon 4, was confirmed by restriction fragment analysis of PCRamplified $5^{\prime}$ region of exon 4 , using the following primers: 5'-CGG CCT GGA TAT CTG TCC CC-3' (forward primer) and 5'-CCC AGT GCC TGC AAA GGC TC-3' (reverse primer). The amplification conditions were $96{ }^{\circ} \mathrm{C}$ for $5 \mathrm{~min}, 96{ }^{\circ} \mathrm{C}$ for $1 \mathrm{~min}$ per $61.1^{\circ} \mathrm{C}$ for $1 \mathrm{~min}$ per $72{ }^{\circ} \mathrm{C}$ for 1 min for 35 cycles, followed by $72{ }^{\circ} \mathrm{C}$ for $5 \mathrm{~min}$. The amplification product (662 bp) was digested with PstI and the fragments were separated by $2 \%$ agarose gel electrophoresis. This procedure was used to screen the mutation in 100 randomly selected normolipidaemic subjects.

Nomenclature of the mutation was according to the recommendations of the Human Genome Variation Society (the numerical series of codons includes the sequence of the signal peptide, http://www.hgvs.org/ mutnomen).

The proband and family members were also genotyped for the following polymorphisms: $-482 \mathrm{C} / \mathrm{T}$ in $A P O C 3$ gene; $\epsilon 2, \epsilon 3$ and $\epsilon 4$ in $A P O E$ gene [19]. The polymorphisms of $A P O A 5$ gene were assessed by direct sequencing.

\section{Ethical aspects}

Informed consent was obtained from the patient and his family and the study protocol was approved by the local ethical committee of the University Hospital of Modena.

\section{Results}

\section{Plasma lipid and lipoproteins}

The plasma lipid levels of the proband, recorded since 2 years of age, are shown in Table 1. Plasma TG level shows large fluctuations over time (especially in early teens), mostly in relation to the compliance of the patient to the low-fat and low-oligosaccharide diet and treatment with $\omega-3$ fatty acids. Plasma HDL-C levels showed minor changes and were less affected by dietary treatment. Plasma lipoprotein profile performed when the patient's TG level was $5.90 \mathrm{mmol} \mathrm{L}^{-1}$ showed a marked increase of the peak corresponding to lipoproteins of density $<1.030 \mathrm{~g} \mathrm{~mL}^{-1}$ (Chylomicrons, VLDL + IDL) and a reduction of LDL and HDL peaks (data not shown). Plasma postheparin LPL activity $(9.5 \mu \mathrm{mol} \mathrm{F}$ FA $\left.\mathrm{mL}^{-1}\right)$ was within the control range (8$15 \mu$ mol FFA $\mathrm{mL}^{-1}$ ). The APOE genotype of the proband was $\epsilon 3 \epsilon 4$. The parents and the brother of the proband were found to have normal lipid levels (Table 2).

\section{Sequence of APOA5 gene}

Since the sequence analysis of $L P L$ and $A P O C 2$ genes in the proband revealed no abnormalitites, we sequenced his APOA5 gene. This analysis revealed that the proband was homozygous for a single nucleotide substitution in exon 4 (c.289 C>T), which converts the glutamine codon at position 97 into a termination codon (Q97X) (Fig. 1). The presence of this mutation was confirmed by restriction fragment analysis after digestion of exon 4 with the restriction enzyme Pst1, one site of which is abolished by the mutation (Fig. 2).

The parents and the brother of the proband were found to be heterozygous for the mutation (Figs 1 and 2). APOA5 gene polymorphisms in the proband's family are shown in Table 3. No carrier of the mutation was found amongst 100 randomly selected normolipidaemic individuals, nor in 30 patients with primary severe HTG negative for mutations in $L P L$ or $A P O C 2$ genes. The proband was homozygous for the common allele in the promoter of $A P O C 3$ gene $(-482$ $\mathrm{C} / \mathrm{C})$, whilst his parents were heterozygous $(-482$ $\mathrm{C} / \mathrm{T})$.

\section{Plasma apo A-V and apo C-III levels}

Apo A-V was undetectable in proband's plasma; the level of apo A-V in proband's father $\left(26.9 \mu \mathrm{g} \mathrm{dL}^{-1}\right)$ was within the control range $\left(25.8 \pm 14.6 \mu \mathrm{g} \mathrm{dL}^{-1}\right)$. Immunoblot analysis of proband's plasma failed to 


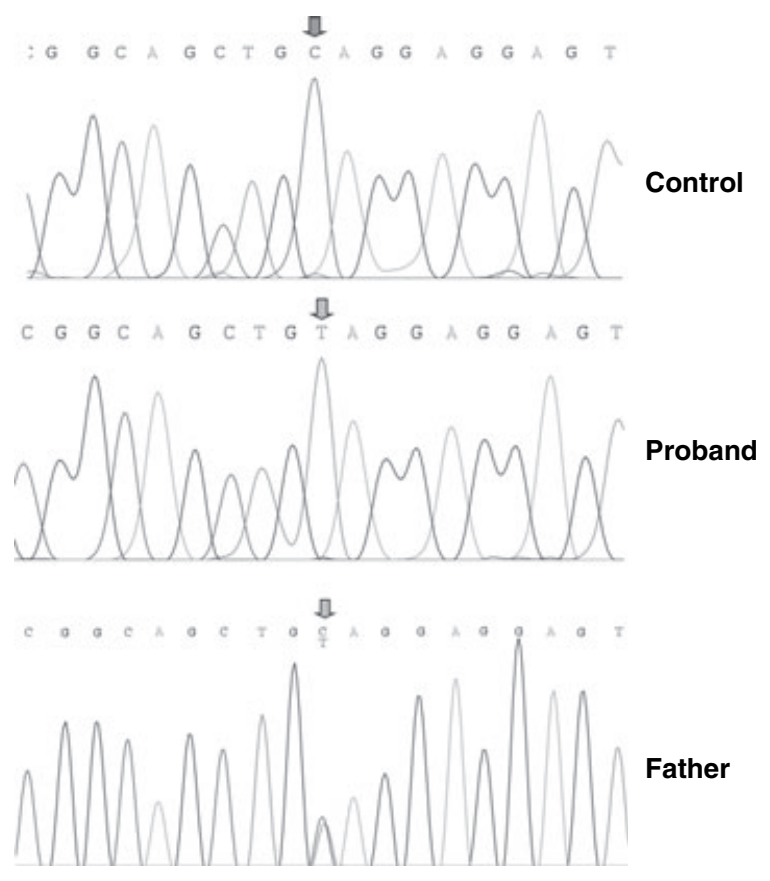

Fig. 1 Partial nucleotide sequence of exon 4 of $A P O A 5$ gene in a control subject, in proband T.L. and in his father. The proband is homozygous for a $\mathrm{C}>\mathrm{T}$ transition (c.289 $\mathrm{C}>\mathrm{T}$ ) converting the glutamine codon at position 97 into a termination codon (Q97X). Proband's father was heterozygous for the same mutation.

reveal the presence of either wild type or truncated apo A-V (Fig. 3). Plasma apo C-III level in the proband was $18.4 \mathrm{mg} \mathrm{dL}^{-1}$ and $10.8 \mathrm{mg} \mathrm{dL}^{-1}$ in his father (in fasting normolipidaemic subjects $10.6 \pm$ $\left.3.6 \mathrm{mg} \mathrm{dL}^{-1}\right)$.

\section{Discussion}

In this study we report a novel mutation in APOA5 gene which causes a complete apo A-V deficiency. This mutation was discovered during a survey of 48 patients with severe primary HTG, suspected to have genetic defects in the lipolytic cascade. Amongst the HTG patients found to be negative for mutations in the $L P L$ and $A P O C 2$ genes ( 30 subjects) we identified three patients who carried pathogenic mutations of APOA5 gene. The clinical and biochemical features of the first two patients were described previously $[18,21]$. The patient investigated in the present study was found to have eruptive xanthomas and milky plasma in the fasting state at the age of 2 years, suggestive of primary hyperchylomicronaemia syndrome. He was put on a restricted dietary regimen (low-fat and low-oligosaccharide diet) which was effective in reducing plasma TG and eliminating eruptive xanthomas. Additional benefits were obtained with supplementation of $\omega-3$ fatty acids. During the 15 years of follow-up plasma TG exceeded the critical level of $10 \mathrm{mmol} \mathrm{L}^{-1}$ (regarded to be the threshold for the risk of pancreatitis) only on one occasion. It is most likely that the strict dietary regimen, the regular physical activity during adolescence and the maintenance of an ideal BMI have contributed to prevent excessive elevations of plasma TG over the years. The normal postheparin LPL activity (performed at the age of 12) cast doubt on the presence of defects in the lipolytic cascade and the patient was referred to the laboratory for molecular diagnosis at the age of 17. After the exclusion of $L P L$ and $A P O C 2$ genes, the analysis of $A P O A 5$ gene showed that proband was homozygous for a point mutation in APOA5 gene, predicted to result in a short truncated protein (Q97X). Neither wild type nor truncated apo A-V was detected in proband's plasma, thus confirming that the patient had a complete apo A-V deficiency. The truncated protein Q97X, if synthesized at all, is expected to be completely devoid of function, as it lacks some domains involved in lipid binding (residues 192-238 and 301343), LPL activation (residues 192-238) and heparin binding (residues 186-227) [22-24].

Phenotypically proband T.L. resembles the patient with complete apo A-V deficiency who was homozygous for the truncated apo A-V Q148X we reported previously [18]. Both these young patients had severe HTG since infancy, which was transmitted as a recessive trait in the family. In both patients the administration of a low-fat diet, especially if supplemented with $\omega-3$ fatty acids, induced a substantial reduction of plasma TG level (Table 4).

Although the mechanism by which apo A-V affects plasma TG level is not fully understood, several hypotheses have been proposed including: (i) an intracellular effect on hepatic VLDL assembly and secretion (apo A-V would down-regulate the assembly and 
(a)

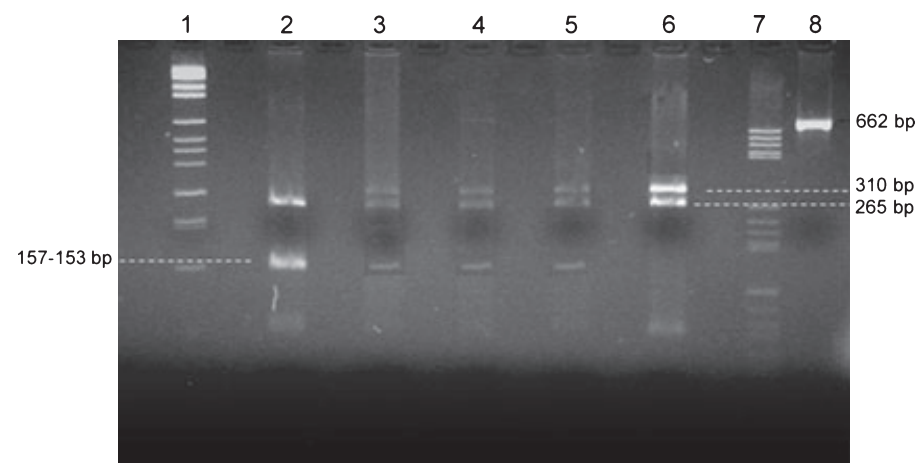

(b)

Control

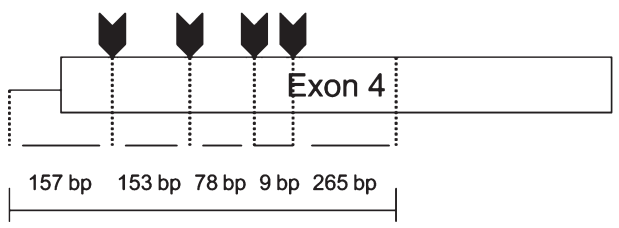

$662 \mathrm{bp}$
Mutant

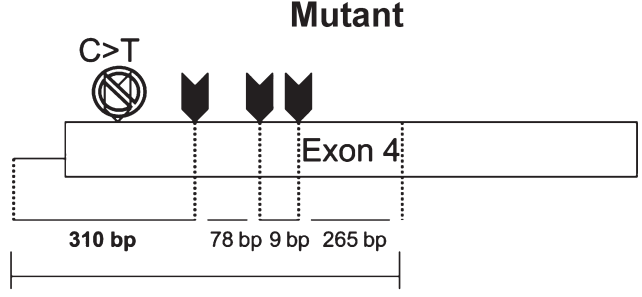

$662 \mathrm{bp}$

Fig. 2 Restriction fragment analysis of exon 4 of $A P O A 5$ gene. Exon 4 was amplified by PCR and digested with the restriction enzyme PstI. The lower panel shows the restriction fragments obtained in a control subject and in proband T.L., in whom the c.289 C>T substitution abolishes a PstI restriction site at the $5^{\prime}$ end of exon 4 . The sizes of the restriction fragments are indicated below the diagram. The upper panel shows the separation of the restriction fragments by $2 \%$ agarose gel electrophoresis. Lanes 1 and 7: molecular weight makers; lane 2: control subject; lanes 3-5: mother, father and brother of the proband; lane 6: proband T.L.; lane 8: undigested PCR fragment of exon 4.

Table 3 APOA5 gene polymorphisms in proband T.L family

\begin{tabular}{llllll}
\hline & $-1131 \mathrm{~T}>\mathrm{C}$ & & $\mathrm{c} .56 \mathrm{C}>\mathrm{G}$ & $\mathrm{IVS} 3+476 \mathrm{G}>\mathrm{A}$ & $\mathrm{c} .1259 \mathrm{~T}>\mathrm{C}$ \\
Subject & (SNP3) & $\mathrm{c} .-3 \mathrm{~A}>\mathrm{G}$ & $(\mathrm{S} 19 \mathrm{~W})$ & (SNP2) & (SNP1) \\
\hline Proband & $\mathrm{T} / \mathrm{T}$ & $\mathrm{A} / \mathrm{A}$ & $\mathrm{C} / \mathrm{C}$ & $\mathrm{G} / \mathrm{G}$ & $\mathrm{T} / \mathrm{T}$ \\
Father & $\mathrm{T} / \mathrm{T}$ & $\mathrm{A} / \mathrm{A}$ & $\mathrm{C} / \mathrm{C}$ & $\mathrm{G} / \mathrm{G}$ & $\mathrm{T} / \mathrm{T}$ \\
Mother & $\mathrm{T} / \mathrm{T}$ & $\mathrm{A} / \mathrm{A}$ & $\mathrm{C} / \mathrm{C}$ & $\mathrm{G} / \mathrm{G}$ & $\mathrm{T} / \mathrm{T}$ \\
Brother & $\mathrm{T} / \mathrm{T}$ & $\mathrm{A} / \mathrm{A}$ & $\mathrm{C} / \mathrm{C}$ & $\mathrm{G} / \mathrm{G}$ & $\mathrm{T} / \mathrm{T}$ \\
& & & & & \\
\hline
\end{tabular}

secretion of VLDL) and (ii) an effect on plasma removal of TG-rich lipoprotein, either by a direct modulation of the activity of lipoprotein lipase or by an effect on the uptake of these lipoproteins (or their remnants) by hepatocytes [24].

Some studies indicate that apo A-V facilitates the action of LPL. In view of its high affinity for heparin, apo A-V would increase the binding of TG-rich lipoproteins to glycosaminoglycans present on the surface of endothelial cells, thus rendering these lipoproteins more accessible to LPL [25]. Recently, Nilsson et al. [26] provided evidence that apo A-V binds to two endocytotic receptors of the LDLR family, LRP and SorLA, and mediates the binding of chylomicrons to these receptors. They also put forward the hypothesis that the main action of apo $A-V$ is exerted at the sinusoidal surface of the hepatocytes rather than in the plasma compartment. Apo A-V (which is synthesized exclusively in the liver) 


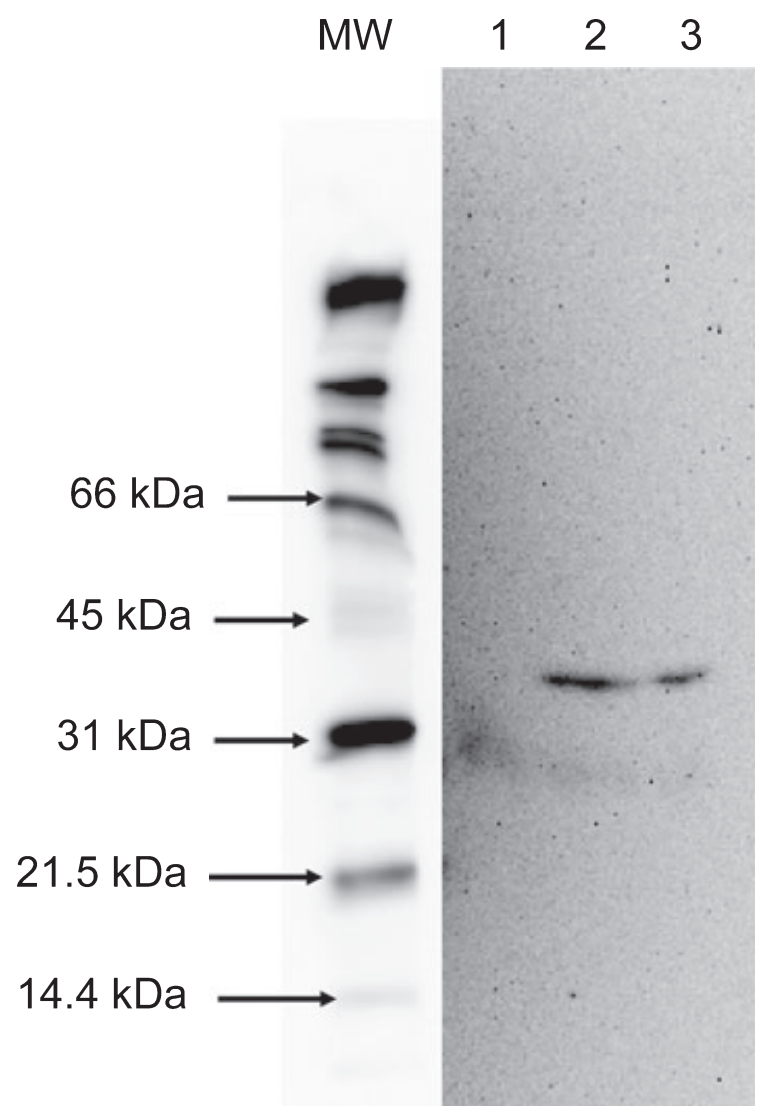

Fig. 3 Immunoblot analysis of plasma apo A-V. Plasma proteins were separated on $10 \%$ SDS-PAGE and transferred to PVDF membranes. Apo A-V was detected using rabbit polyclonal antibodies directed against apo A-V and appropriate secondary antibody. Signals were visualized by chemiluminesence. Five microlitre of plasma was applied to each lane. Lane 1: proaband T.L.; lane 2: proband's father; lane 3: control subject. Molecular weight markers are shown on the left.

secreted by the hepatocytes would be entrapped by heparan-sulphate proteglycans and endocytotic receptors present at the cell surface [27]. In this way apo A-V would facilitate lipoprotein uptake (i.e. chylomicron remnants removal). These results are in line with the observation that the clearance of chylomicron remnants is reduced in apoa 5 knock-out mice [28]. In this context one might assume that in patients with apo A-V deficiency the LPL- mediated TG hydrolysis of chylomicrons and VLDL is less efficient and the clearance of lipoprotein remnants by the liver is delayed. The magnitude of the accumula- tion in plasma of TG- rich lipoproteins in these patients is probably related to the amount of these lipoproteins entering the plasma compartment. Excessive secretion of chylomicrons due to a high fat intake, or excessive secretion of VLDL by the liver induced by various metabolic stimuli, may overload the less efficient LPL-mediated hydrolysis of TG-rich lipoproteins and impair the capacity of the liver to capture lipoprotein remnants, in case of apo A-V deficiency. This may explain why in our two patients with apo A-V deficiency (Q97X and Q148X) dietary interventions, aimed at reducing chylomicron formation (reduced oral fat load) and/or VLDL synthesis and secretion (administration of $\omega-3$ fatty acids) [29], have such a profound TG-lowering effect.

The other remarkable finding in proband T.L. is the persistently low level of plasma HDL-C, which was only marginally affected by dietary treatment. The hypothesis that the absence of apo A-V, which is a minor protein component of HDL, renders HDL more unstable and more easily removed from the circulation, is unlikely in view of the minute amounts of apo $\mathrm{A}-\mathrm{V}$ present in human plasma. It is more likely that the delayed TG hydrolysis, due apo A-V deficiency per se or due to the increased level of apo C-III (an inhibitor of LPL) [30], reduces the availability of surface components of TG-rich lipoproteins, which contribute to HDL formation. It was recently shown that adenovirus mediated delivery of apoA-V into HTG APOC3 transgenic mice not only reduced triglyceride and VLDL-C level but also increased HDL-C level with an increase of both the number and size of HDL particles [31]. These data suggest that in addition to its TG-lowering effects, apoA-V plays a significant role in modulating HDL maturation and cholesterol metabolism.

The three heterozygotes for Q97X mutation investigated in this study (Table 2) have normal plasma TG, suggesting that partial apo A-V deficiency is not sufficient per se to induce HTG and other predisposing factors are required. We previously reported that only five out of ten carriers of Q148X mutation had moderate elevation of plasma $\mathrm{TG}\left(>2 \mathrm{mmol} \mathrm{L}^{-1}\right.$; the 
Table 4 Main clinical features of the patients homozygous for nonsense mutations of $A P O A 5$ gene

\begin{tabular}{llllll}
\hline $\begin{array}{l}\text { ApoA-V } \\
\text { mutation }\end{array}$ & $\begin{array}{l}\text { Plasma TG } \\
\mathrm{mmol} \mathrm{L}^{-1}\end{array}$ & $\begin{array}{l}\text { Plasma } \\
\text { apoA-V }\end{array}$ & Pancreatitis & $\begin{array}{l}\text { APOE } \\
\text { genotype }\end{array}$ & Reference \\
\hline Q97X & 9.65 & undetectable & No & $\epsilon 3 / \epsilon 4$ & present study \\
Q139X & $15-30$ & n.d. & Yes & $\epsilon 3 / \epsilon 3$ & {$[19]$} \\
Q148X & 50.16 & undetectable & No & $\epsilon 3 / \epsilon 3$ & {$[17,18]$} \\
\hline
\end{tabular}

nd, not determined.

${ }^{\mathrm{a}}$ Deceased at the age of 60 from a cause unrelated to dyslipidaemia [19]

highest level observed was $4.65 \mathrm{mmol} \mathrm{L}^{-1}$ ). Carriers with elevated plasma TG tended to be older, to have higher body mass index and higher fasting plasma glucose level than normotriglyceridaemic carriers [18]. Amongst the carriers of Q139X belonging to one of the families reported by Marcais et al. [19], two had severe HTG and four had plasma TG levels of $2 \mathrm{mmol} \mathrm{L}^{-1}$ or less. The two individuals with severe HTG had diabetes and low LPL activity.

In conclusion, we report the third mutation in $A P O A 5$ gene that results in apo A-V deficiency in a patient with primary HTG. We also confirmed that strict dietary treatment and supplementation with $\omega-3$ fatty acids induce a substantial reduction of plasma TG level.

We predict that the systematic analysis of the major candidate genes controlling the lipolytic cascade in patients with primary HTG will lead to the discovery of other loss of function mutations of APOA5 gene.

\section{Conflict of interest}

No conflict of interest was declared.

\section{Acknowledgements}

This study was supported by a grant of the Ministry of University and Research of Italy to S. Calandra (grant no. 2005061114_002).

\section{References}

1 Hegele RA. Monogenic dyslipidemias: window on determinants of plasma lipoprotein metabolism. Am J Hum Genet 2001; 69: 1161-71.
2 Brunzell JD, Deeb SS. Familial lipoprotein lipase deficiency, apoC-II deficiency, and hepatic lipase deficiency. In: Scriver $\mathrm{CR}$, Beaudet AL, Sly WS, Valle D, eds. The Metabolic and Molecular Bases of Inherited Diseas. New York: MCGraw Hill, 2001; 2789-816.

3 Durrington P. Dyslipidemia. Lancet 2003; 362: 717-31.

4 Eichenbaum-Violine S, Olivier M, Jones EL et al. Linkage and association between distinct variants of the APOA1/C3/A4/A5 gene cluster and familial combined hyperlipidemia. Arterioscler Thromb Vasc Biol 2004; 24: 167-75.

5 Lee JC, Lusis AJ, Pajukanta P. Familial combined hyperlipidemia: upstream transcription factor 1 and beyond. Curr Opin Lipidol 2006; 17: 101-9.

6 Pennacchio LA, Rubin EM. Apolipoprotein A5, a newly identified gene that affects plasma triglyceride levels in human and mice. Arterioscler Thromb Vasc Biol 2003; 23: 529-34.

7 Talmud PJ, Hawe E, Martin S et al. Relative contribution of variation within the APOC3/A4/A5 gene cluster in determining plasma triglycerides. Hum Mol Genet 2002; 11: 303946.

8 Aouizerat BE, Kulkami M, Heilbron D et al. Genetic analysis of a polymorphism in the human apoA-V gene: effect on plasma lipids. J Lipid Res 2003; 44: 1167-73.

9 Klos KLE, Hamon S, Clark AG, Boewinkle E, Liu K, Sing CE. APOA5 polymorphims influence plasma triglycerides in young healthy African Americans and whites of the CARDIA Study. J Lipid Res 2005; 46: 564-70.

10 Wright WT, Young IA, Nicholls DP, Patterson C, Lyttle K, Graham CA. SNPs at the APOA5 gene account for the strong association with hypertriglyceridemia at the APOA5/A4/C3/A1 locus on chromosome 11q23 in the Northern Irish population. Atherosclerosis 2006; 185: 353-60.

11 Schaap FG, Nierman MC, Berbèe JFP et al. Evidence for a complex relationship between apoA-V and apoC-III in patients with severe hypertriglyceridemia. J Lipid Res 2006; 47: 23339.

12 Talmud PJ, Cooper JA, Hattori H, Miller P, Miller GJ, Humphries SE. The apolipoprotein A-V genotype and plasma apolipoprotein $\mathrm{A}-\mathrm{V}$ and triglyceride levels: prospective risk of type 2 diabetes. Results from the Northwick Park Heart Study I. Diabetelogia 2006; 49: 2337-40.

13 Vaessen SFC, Schaap FG, Kuivenhoven J-A et al. Apolipoprotein $\mathrm{AV}$, triglycerides and risk of future coronary artery disease in apparently healthy men and women: the prospective EpicNorfolk population study. J Lipid Res 2006; 47: 2064-70. 
14 Dallinga-Thie GM, van Tol A., Hattori H, van Vark-van der Zee LC, Jansen H, Sijbrands EJG. Plasma apolipoprotein A5 and triglycerides in type 2 diabetes. Diabetologia 2006; 49: $1505-11$.

15 Alborn WE, Prince MJ, Konrad RJ. Relationhisp of apolipoprotein $\mathrm{A} 5$ and apolipoprotein $\mathrm{C} 3$ levels to serum triglycerides in patients with type 2 diabetes. Clin Chim Acta 2007; 378: 154 8.

16 Henneman P, Schaap FG, Havekes L et al. Plasma apoAV levels are markedly elevated in severe hypertriglyceridemia and positively correlated with the APOA5 S19W polymorphism. Atherosclerosis 2007; 193: 129-34.

17 Calandra S, Priore Oliva C, Tarugi P, Bertolini S. APOA5 and triglyceride metabolism, lesson from human $A P O A 5$ deficiency. Curr Opin Lipidol 2006; 17: 122-7.

18 Priore Oliva C, Pisciotta L, Li Volti G et al. Inherited apolipoprotein A-V deficiency in severe hypertriglyceridemia. Arterioscler Thromb Vasc Biol 2005; 25: 411-7.

19 Marcais C, Verges B, Charrière S et al. ApoA5 Q139X truncation predisposes to late-onset hyperchylomicronemia due to lipoprotein lipase impairment. J Clin Invest 2006; 115: 2862-9.

20 Chapman MJ, Goldstein S, Lagrange D, Laplaud PM. A density gradient ultracentrifugation procedure for the isolation of the major lipoprotein classes from human serum. J Lipid Res 1981; 22: $339-58$

21 Priore Oliva C, Tarugi P, Calandra $\mathrm{S}$ et al. A novel sequence variant in $A P O A 5$ gene found in patients with severe hypertriglyceridemia. Atherosclerosis 2006; 188: 215-7.

22 Sun G, Bi N, Li G et al. Identification of lipid binding and lipoprotein lipase activation domains of human apoAV. Chem Phys Lipids 2006; 143: 22-38.

23 Lookene A., Beckstead JA, Nilsson S, Olivecrona G, Ryan RO. Apolipoprotein A-V heparin interactions-implications for plasma lipoprotein metabolism. J Biol Chem 2005; 280: 25385-7.
24 Wong K, Ryan RO. Characterization of apolipoprotein A-V structure and mode of plasma triacylglycerol regulation. Curr Opin Lipidol 2007; 18: 319-24.

25 Merkel M, Leoffler B, Kluger $\mathrm{M}$ et al. Apolipoprotein AV accelerates plasma hydrolysis of triglyceride rich lipoproteins by interaction with proteglycan bound lipoprotein lipase. $J$ Biol Chem 2005; 280: 21553-60.

26 Nillson SK, Lookene A, Beckstead JA, Gliemann J, Ryan RO, Olivecrona G. Apolipoprotein A-V interaction with members of the low density lipoprotein receptor gene family. Biochemistry 2007; 46: 2896-3904.

27 Mahley RW, Huang Y. Atherogenic remnant lipoproteins: role for proteoglycans in trapping, transferring, and internalizing. J Clin Invest 2007; 117: 94-8.

28 Grosskopf I, Baroukh N, Lee S-J et al. Apolipoprotein A-V deficiency results in marked hypertriglyceridemia attributable to decreased lipolysis of triglyceride-rich lipoproteins and removal of their remnants. Arterioscler Thromb Vasc Biol 2005; 25: 2573-9.

29 Davidson $\mathrm{MH}$. Mechanisms of the hypotriglyceridemic effect of marine omega-3 fatty acids. Am J Cardiol 2006; 98: 27i-33i.

30 Wang C-S, McConathy WJ, Kloer HU, Alaupovic P. Modulation of lipoprotein lipase activity by apolipoproteins. Effects of apolipoprotein C-III. J Clin Invest 1985; 75: 384-90.

31 Qu S, Perdomo G, Su D, D'Souza FM, Shachter NS, Dong $\mathrm{HH}$. Effects of apoA-V on HDL and VLDL metabolism in APOC3 transgenic mice. J Lipid Res 2005; 48: 1476-87.

Correspondence: Sebastiano Calandra, Department of Biomedical Sciences, University of Modena \& Reggio Emilia, Via campi 287, I-41100 Modena, Italy.

(fax: +39 0592055 426; e-mail. sebcal@unimore.it). 